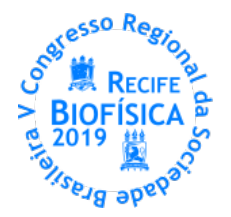

\title{
O TAMANHO DA CADEIA ALQUIL DE LÍQUIDOS IÔNICOS IMIDAZÓLICOS INFLUENCIA NA CITOTOXICIDADE DE CÉLULAS-TRONCO MESENQUIMAIS DO CORDÃO UMBILICAL HUMANO
}

\author{
Wyndly Daniel Cardoso Gaião ${ }^{* *}$, Paloma Lys de Medeiros², Márcia Bezerra da Silva1, Dijanah Cota Machado", \\ Cláudio Gabriel Rodrigues ${ }^{1}$
}

\author{
${ }^{1}$ Departamento de Biofísica e Radiobiologia, Laboratório de Biofísica das Membranas e Células-Tronco Dr. Oleg Krasilnicov, UFPE \\ ${ }^{2}$ Departamento de Histologia e Embriologia, Laboratório de Cultura de Tecidos, UFPE \\ *wyndly@hotmail.com
}

\begin{abstract}
INTRODUÇÃO
Líquidos lônicos (Lls) são sais orgânicos compostos exclusivamente por cátions orgânicos e ânions orgânicos ou inorgânicos com ponto de fusão abaixo de $100^{\circ} \mathrm{C}$ (AMDE et al, 2015). Nos últimos anos, os Lls têm sido destaque em relação aos demais solventes orgânicos devido a suas propriedades físico-químicas, tais como: pressão de vapor insignificante, baixa volatilidade, estabilidade térmica e química, baixa inflamabilidade, capacidade de solvatação e reciclabilidade (PHAN et al, 2010). Os LIs são considerados "solventes verdes" e gradualmente podem substituir os tradicionais solventes orgânicos voláteis usados em vários processos farmacêuticos e químicos (ERGONOVA et al, 2014). Por outro lado, vários estudos recentes demostraram que os LIs podem ser bioacumulados em ecossistemas aquáticos e possivelmente tóxicos para alguns organismos, que incluem: algas, crustáceos, caracóis e peixes (LATALA et al, 2009; Ll et al, 2013; MA et al, 2014). Além da toxicidade de Lls em organismos aquáticos, demonstrou-se também que os LIs são citotóxicos para linhagens celulares humanas, como HepG2 (Ll et al, 2015), HeLa (WANG et al, 2007), CaCo-2 e HT-29 (FRADE et al, 2007), porém poucos estudos desses efeitos foram relatados em células-tronco mesenquimais do cordão umbilical humano (CTMs). Células-tronco (CTs) são células progenitoras capazes de se diferenciar em células de tecidos adultos especializados (XU et al, 2013). Células-Tronco Mesenquimais (CTMs) são multipotentes e podem se diferenciar em diversas linhagens, tais como: adipogênicas, osteogênicas, condrogênicas, indicando assim sua multipotencialidade (KIM et al, 2013). As CTMs podem ser usadas na regeneração tecidual, engenharia genética e terapia celular graças ao potencial proliferativo e de diferenciação em múltiplas linhagens celulares (PAREKKADAN; MILWID, 2010). Nesse contexto, analisamos a citotoxicidade dos LIs: Cloreto de 1-etil-3metilimidazólio (EMIM-Cl), Cloreto de 1-butil-3-metilimidazólio (BMIM-Cl), Cloreto de 1-hexil-metilimidazólio (HMIM-Cl) e Cloreto de 1-decil-3-metilimidazólio (DMIM-Cl) nas CTMs. Os LIs imidazólicos foram amplamente investigados nos últimos anos (PHAM et al, 2010) e foram recomendados pelo Programa Nacional de Toxicologia dos Estados Unidos e pelo Instituto Nacional de Ciências da Saúde e Ambiental para testes toxicológicos (CHO et al., 2008).
\end{abstract}

\section{MATERIAIS E MÉTODOS}

Os cordões umbilicais foram doados voluntariamente por parturientes saudáveis, submetidas à cirurgia cesariana no Hospital De Ávila (comitê de ética, protocolo 49503715.0.0000.5208). A obtenção das células foi realizada conforme a técnica da migração espontânea (MITCHELL et al., 2003; ISHIGE et al., 2009). Resumidamente, os cordões foram lavados e as veias perfundidas com solução salina tampão fosfato (PBS) para retirada do sangue. Então, os cordões foram cirurgicamente cortados transversalmente em pequenos pedaços (aproximadamente $2 \mathrm{~cm}$ de comprimento), removendo veia e artérias, que foram descartadas e o tecido gelatinoso contendo a geleia de Wharton foi então fragmentado e transferido para garrafas de cultura estéreis $\left(75 \mathrm{~cm}^{2}\right)$ contendo meio Low DMEM (Gibco) suplementado com $10 \%$ de soro fetal bovino (SFB, Gibco), $20 \%$ de fator de crescimento (F12, Gibco) e 1\% de antibióticos (penicilina e estreptomicina) em incubadora a $37^{\circ} \mathrm{C}$, $80 \%$ de umidade e $5 \%$ de $\mathrm{CO}_{2}$. Todas as CTMs utilizadas estavam na segunda passagem. 0 teste de citotoxicidade foi realizado de acordo com a técnica colorimétrica do MTT (Brometo Tiazolil azul de Tetrazólio) (MOSMANN 1983). As CTMs foram distribuídas em placa de 96 poços com uma concentração de $1 \times 10^{4}$ células/poço. As CTMs do grupo controle foram mantidas apenas em meio de cultura. No grupo teste, as CTMs foram expostas ao EMIM-Cl, BMIM-Cl, HMIM-Cl nas concentrações: $100,500,2.500,10.000$ ou $50.000 \mu \mathrm{M}$; para o DMIM-Cl: $0.001,0.1,1,10$ ou $100 \mu \mathrm{M}$ (Sigma-Aldrich, USA). A representação esquemática da estrutura química dos LIs, com tamanho variável da cadeia alquil empregados nesse estudo, está representada na figura 1. Após 72 horas, foram adicionados $20 \mu \mathrm{L}$ do MTT $(5 \mathrm{mg} / \mathrm{mL})$, e a placa foi incubada por mais quatro horas. Posteriormente foram adicionados $100 \mu \mathrm{L}$ de dimetilsulfóxido (DMSO) a cada poço, visando a solubilização dos cristais de formazan. As leituras da densidade óptica foram obtidas a $595 \mathrm{~nm}$ em espectrofotômetro (Varioskan, ThermoScientific, USA). A análise morfológica das CTMs realizou-se após 72 horas de sua exposição aos LIs EMIM-Cl, BMIM-Cl e HMIM-Cl nas concentrações de 100 ou 100.000 $\mu \mathrm{M}$; para o DMIM-Cl: 0.001 ou $100 \mu \mathrm{M}$. As fotomicrografias foram aquisitadas por uma de câmera (MOTICAN2000, MOTIC, BR) acoplado à microscópio invertido (LEICA, DM IL, USA). Os dados estão apresentados como a média \pm desvio padrão de três experimentos em triplicata.

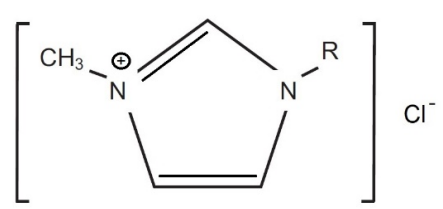

Figura 1. Estrutura química geral dos Lls utilizados no estudo. $O$ radical $R$ variou entre os grupos etil (dois carbonos), butil (quatro carbonos), hexil (seis carbonos) e decil (dez carbonos). 


\section{RESULTADOS E DISCUSSÃO}

$\mathrm{Na}$ figura 2 observam-se as alterações morfológicas induzidas pelos LIs nas Células-Tronco Mesenquimais do Cordão Umbilical Humano (CTMs). Nas baixas concentrações de Lls, as CTMs apresentaram aumento de granulações citoplasmáticas (Figura 2 C, E, G) e finas projeções citoplasmáticas em formato de agulhas, com aumento do espaçamento intercelular (Figura $2 \mathrm{I}$ ). Em maiores concentrações, os Lls induziram retrações celulares (Figura 2 D, F, H, J). Adicionalmente foram observados debris e maior tendência ao agrupamento celular (Figura $2 \mathrm{H}, \mathbf{J}$ ). A presença desses achados morfológicos foi dependente da extensão da cadeia lateral dos Lls. Como já demonstrado em outros relatos, essas alterações morfológicas são característicos do processo de apoptose (CHEN et al., 2014) ou de destruição direta da membrana plasmática (WANG et al., 2007).

$\mathrm{Na}$ Tabela 1 é representado os valores das $\mathrm{IC}_{50}$ para os $\mathrm{LIs} \mathrm{EMIM-Cl}$, $\mathrm{BMIM}-\mathrm{Cl}$, $\mathrm{HMIM}-\mathrm{Cl}$ e DMIM-Cl.

Tabela 1. Valores de $\mathrm{IC}_{50}$ dos Lls para as Células-Tronco Mesenquimais do Cordão Umbilical Humano (CTMs).

\begin{tabular}{|c|c|}
\hline Líquido lônico & $I C_{50}$ \\
\hline EMIM-Cl & $12,37 \pm 1,48 \mathrm{mM}$ \\
\hline$B M I M-C I$ & $5,33 \pm 1.87 \mathrm{mM}$ \\
\hline $\mathrm{HMIM}-\mathrm{Cl}$ & $2,38 \pm 1,69 \mathrm{mM}$ \\
\hline DMIM-Cl & $5,22 \pm 2,18 \mu \mathrm{M}$ \\
\hline
\end{tabular}

Todos os Lls, nas concentrações utilizadas, influenciaram na viabilidade das CTMs. Esses LIs também alteraram a viabilidade em outras linhagens de células humanas, como HeLa (WANG et al, 2007) e carcinoma pulmonar (CHEN et al, 2014). Nos LIs com cadeia alquil de dois a seis carbonos, notou-se um fator de aproximadamente $2 \times$ no decréscimo da concentração inibitória $\left(I_{50}\right)$. Por outro lado, observamos um fator de aproximadamente $1000 \times$, no caso do LI de 10 carbonos. Deste modo, observa-se que a ação citotóxica dos Lls foram dose e estrutura dependentes do tamanho de sua cadeia hidrofóbica. Nossos resultados refletem a sensibilidade de uma linhagem celular indiferenciada à ação dos LIs. Igualmente o comprimento da cadeia lateral também influencia na citotoxicidade em outras linhagens celulares diferenciadas, tais como: Células leucêmicas (STOLTE et al, 2006); células HeLa (WANG et al., 2007); Carcinoma pulmonar (CHEN et al, 2014).

\section{CONCLUSÕES}

A sensibilidade das Células-Tronco Mesenquimais do Cordão Umbilical Humano aos danos induzidos pelos Lls imidazólicos é dependente do comprimento de sua cadeia alquil.

\section{REFERÊNCIAS}

AMDE, M.; LIU, J. F.; PANG, L. Environmental Application, Fate, Effects, and Concerns of lonic Liquids: A Review. Environ. Sci. Technol., v. 49, p. 12611-12627, 2015.

BUBALO, M. C. et al. Cytotoxicity towards CCO cells of imidazolium ionic liquids with functionalized side chains: Preliminary QSTR modeling using regression and classification based approaches. Ecotoxicology and Environmental Safety, v. 112, p. 22-28, 2015.

CHEN, H. L. et al. Cytotoxicity of Imidazole Ionic Liquids in Human Lung Carcinoma A549 Cell Line. Journal of the Chinese Chemical Society, v. 61. p. 763-769, 2014.

$\mathrm{CHO}, \mathrm{C}$. W. et al. The ecotoxicity of ionic liquids and traditional organic solvents on microalga Selenastrum capricornutum. Ecotoxicology and Environmental Safety, v. 71, p. 166-171, 2008.
EGOROVA, K. S.; ANANIKOV, V. P. Toxicity of Ionic Liquids: Eco(cyto)activity as Complicated, but Unavoidable Parameter for Task-Specific Optimization. ChemSusChem, v. 7, 336 - 360, 2014.

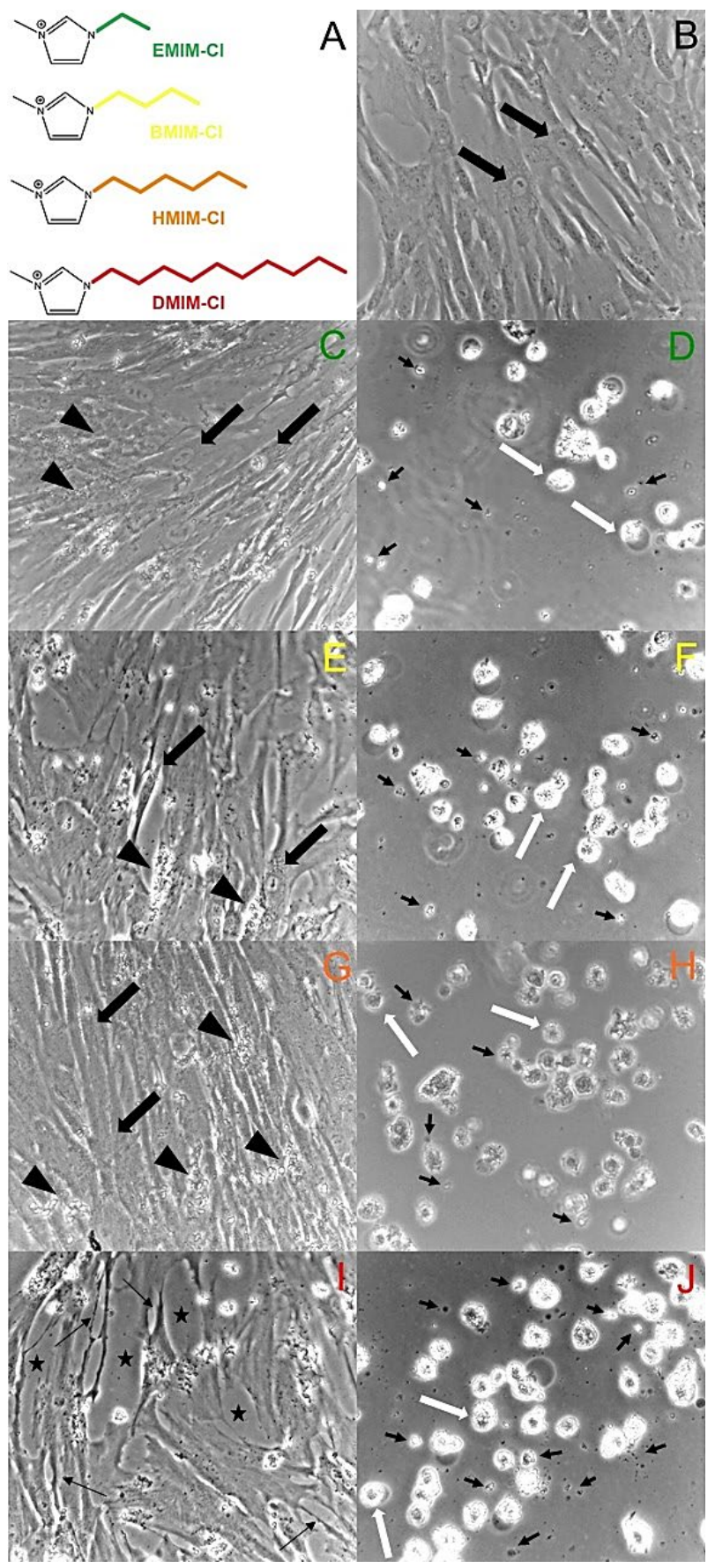

Figura 2. Alterações morfológicas induzidas por Lls nas células-tronco mesenquimais de cordão umbilical humano (CTMs). A) Representação estrutural dos cátions de LI (verde, EMIM-Cl; amarelo, BMIM-Cl; laranja, HMIM-Cl e vermelho, DMIM-Cl). B) Fotomicrografia de CTMs com morfologia fibroblastóides (setas pretas grossas) formando monocamada (Grupo controle). C, E e G) Células com formas fibroblastóides (setas pretas grossas) e presença de granulações citoplasmáticas (cabeças de setas) que aumentam de forma dependente com a extensão da cadeia lateral do LI. I) As células apresentam finas projeções citoplasmáticas (setas finas) em formato de agulhas e espaçamentos (estrelas), quando comparadas ao Grupo controle. D e F) Células totalmente retraídas com formas arredondadas (setas brancas) e presença de debris (setas curtas); H e J) Presença de células arredondas (setas brancas) com tendência ao agrupamento; debris (setas curtas) também estão presentes em maior densidade. As células foram expostas as seguintes concentrações de Lis: C, $100 \mu \mathrm{M}$ de EMIM-Cl; D, $100.000 \mu \mathrm{M}$ de EMIM-Cl; E, $100 \mu \mathrm{M}$ de BMIM-Cl; F, 100.000 $\mu \mathrm{M}$ de BMIM-Cl; G, $100 \mu \mathrm{M}$ de HMIM-Cl; H, $100.000 \mu \mathrm{M}$ de HMIM-Cl; I, $0.001 \mu \mathrm{M}$ de DMIM-Cl; $\mathrm{J}, 100 \mu \mathrm{M}$ de DMIM-Cl. 
FRADE, R. F. M. et al. Effect of ionic liquids on human colon carcinoma HT-29 and CaCo-2 cell lines. Green Chemistry, v. 9, p. 873-877, 2007.

ISHIGE, I. et al. Comparison of mesenchymal stem cells derived from arterial, venous, and Wharton's jelly explants of human umbilical cord. International Journal of Hematology, v. 90, p. 261-269, 2009. KIM, D. W. et al. Wharton's Jelly-Derived Mesenchymal Stem Cells: Phenotypic Characterization and Optimizing Their Therapeutic Potential for Clinical Applications. International Journal of Molecular Sciences, v. 14, p. 11692-11712, 2013.

LATALA, A. et al. Toxicity of imidazolium and pyridinium based ionic liquids towards algae. Bacillaria paxillifer (a microphytobenthic diatom) and Geitlerinema amphibium (a microphytobenthic blue green alga). Green Chemistry, v. 11, p. 1371- 1376, 2009.

LI, X.; MA, J.; WANG, J. Cytotoxicity, oxidative stress, and apoptosis in HepG2 cells induced by ionic liquid 1-methyl-3-octylimidazolium bromide. Ecotoxicology and Environmental Safety, v. 120, p. 342348, 2015.

MA, J. Toxicity of Imidazolium-Based Ionic Liquids on Physa Acuta and the Snail Antioxidant Stress Response. J. Biochem. Mol. Toxicol., v. 28, p. 69-75, 2014.

MITCHELL, K. E. et al. Matrix cells from Wharton's jelly form neurons and glia. Stem cells, v. 21, p. 50-60, 2003.

MOSMANN, T. Rapid Colorimetric Assay for Cellular Growth and Survival: Application to Proliferation and Cytotoxicity Assays. Journal of Immunological Methods, v. 65, p. 55-63, 1983.

PAREKKADAN, B.; MILWID; J. M. Mesenchymal Stem Cells as Therapeutics. Annual Review of Biomedical Engineering, v. 12, p. 87-117, 2010.

PHAM, T. P. T.; CHO, C. W.; YUN, Y. S. Environmental fate and toxicity of ionic liquids: A review. Water Research, v. 44, p. 352372, 2010.

STOLTE, S. et al. Anion effects on the cytotoxicity of ionic liquids. Green Chemistry, v. 8, p. 621-629, 2006.

WANG, $X$. et al. Cytotoxicity of ionic liquids and precursor compounds towards human cell line HeLa. Green Chemistry, v. 9, p. 1191-1197, 2007.

$\mathrm{XU}, \mathrm{X}$. L. et al. Progress and prospects in stem cell therapy. Acta Pharmacologica Sinica, v. 34, p. 741-746, 2013. 